\begin{tabular}{lcl}
\hline Bentham OPEN & The Open PSychology Journal \\
CrossMark & Content list available at: www.benthamopen.com/TOPSYJ/ & DOI: $10.2174 / 1874350101710010127$ \\
\hline
\end{tabular}

RESEARCH ARTICLE

\title{
At-Risk Teachers: The Association Between Burnout Levels and Emotional Appraisal Processes
}

\author{
Caterina Fiorilli, ${ }^{1, *}$, Alessandro Pepe ${ }^{2}$, Ilaria Buonomo ${ }^{1,3}$ and Ottavia Albanese ${ }^{2}$ \\ ${ }^{I}$ Human Sciences Department, LUMSA University, Rome, Italy \\ ${ }^{2}$ Human Sciences Department, University of Bicocca, Milan, Italy \\ ${ }^{3}$ Department of Psychology of Education and Socialization Processes, Sapienza University, Rome, Italy
}

\section{Abstract: \\ Background:}

Teachers are at-risk of burnout due to continuous emotional demands. Existing research suggests that there is a strong relationship between the burnout phenomenon and teachers' propensity to experience unpleasant emotions.

\section{Objective:}

The current study examined whether teachers' levels of burnout affect the process by which they appraise school-life events that elicit negative emotions.

\section{Methods:}

Participants were 316 school teachers. Teachers' appraisal of both students' negative emotion intensity (SAE) and their own negative emotion intensity (TAE) was evaluated via the Emotional Competence Questionnaire. Teachers' burnout levels were measured using the Maslach Burnout Inventory. The main hypothesis was tested by using SEM to assess a full model.

\section{Results:}

The findings suggest that burnout compromises teachers' appraisal of both their students' and their own negative emotion intensity.

\section{Conclusion:}

We discuss how our main findings may be interpreted and explore their implications for educational settings.

Keywords: Emotional appraisal, Burnout, Teachers, Emotion regulation, SAE, TAE.

\section{INTRODUCTION}

\subsection{Emotional Appraisal Process and Affect States}

Emotional processing is a multidimensional activity that includes appraisal of an event, subjective experience, physiological change, emotion expression, and action tendencies [1 - 4]. Experiencing events that cause emotions requires individuals to engage in judgment or appraisal of significance or relevance of these occurrences vis-à-vis their own personal motives, goals, or concerns [5 - 7]. Appraisal theory represents a cognitive approach to emotional processing.

\footnotetext{
* Address correspondence to this author at the Human Sciences Department, LUMSA University, Rome, Italy; Tel/Fax: +39 0668422913; E-mail: fiorilli@lumsa.it
} 
When assessing events and situations, individuals compare expected and experienced environmental conditions. This may yield a match (eliciting positive emotion) or a mismatch (eliciting negative emotion) between the actual and expected state of affairs. In educational settings, for example, teachers experience positive emotions when they acknowledge students' motivation and commitment [7] and negative emotions when they feel unable to manage students' misbehavior [8 - 10]. Appraisal theory states that emotion in an individual is elicited by a psychological appraisal which involves evaluating and judging events and situations. Hence, it is the individual's appraisal of the situation that elicits specific emotions [5] and the specific meaning attributed to a particular event may explain the quality of the resulting emotion experience. In other words, the appraisal theory of emotions accounts for why the same external event does not necessarily lead to the same emotions in different individuals or, to put it another way, why there are individual differences in the emotions that people experience in response to the same events. Consequently, the quality and intensity of the elicited emotion will not depend on the situation itself, but on a person's subjective evaluation of the situation in terms of a set of appraisal dimensions.

In relation to educational settings, the role of appraisal in the emotions experienced by teachers has been extensively studied. Teachers' perceptions of and expectations concerning their own personal characteristics, relationships with students and colleagues, school resources and demands can have a major influence on their emotional experiences at school. For example, teachers who view themselves as capable of managing organizational and relational demands at school feel less anxious about their professional role [11].

Furthermore, numerous have shown that individuals acquire information about the social environment and events, and consequently modulate their emotional and behavioral responses, by observing others. For example, other peoples' emotional expressions are used as a source of information, such that when people interact, mutual emotional and affective expressions fulfill a regulatory function [12 - 14]. Accordingly, Lazarus [15] stated that emotions are intrinsically relational: therefore, the ability to correctly evaluate the type and intensity of other people's emotions is of key importance, as this process endows relational meaning on one's interactions.

In line with such findings, some authors have found that individuals decide how to react and respond to social situations according to their perceptions of others' facial expressions and past experiences with them [16, 17].

Interestingly, a circular dynamic has been observed, whereby affect states appear to influence cognitive processing $[18,19]$. According to several authors, emotion plays a key role in cognitive processes such as decision-making and judging events [20 - 22]. Angie and colleagues [23] found that major affect states (e.g., sadness, anger, fear or anxiety, happiness) have significant effects on judgment, while positive and negative emotions influence the recognition of emotional cues. For example, it has been found that while low positive emotion is associated with a high threshold for recognizing happiness, high negative emotion is associated with a low threshold for recognizing disgust and dislike [24]. In a recent work, Schmidt and Mast [25] showed that both sad and happy emotions hindered the recognition of mood-opposite emotion expression; furthermore, individuals experiencing negative emotions, as compared with people experiencing neutral or happy emotions, are better at recognizing negative stimuli and worse at interpreting ambiguous or positive stimuli vice versa, people experiencing positive emotions tend to be better at recognizing positive stimuli than negative ones, compared to people experiencing neutral or negative emotions. Furthermore, information processing concerning facial emotion expressions differs as a function of affect states: while sad individuals are processing faces, they attend to details, while happy individuals attend to global information. Similarly, Lee and colleagues [26] showed that people in a sad affect state tend to classify ambiguous emotional stimuli as negative rather than positive. In line with these findings, depression has been identified in several studies as a condition in which individuals tend to display altered appraisal processes. In a recent review, Berking and Whitley [27] found that people with depression symptoms report difficulty in identifying their emotions, accepting and tolerating negative emotions, practicing compassionate self-support when suffering from negative emotions, and effectively modifying their own emotions. Furthermore, according to Frijda [28], appraisal and emotion regulation strategies are key predictors of emotion intensity. Overall, research on emotion intensity is of great clinical importance, given that negative emotions are associated with mental health disorders [9].

In sum, from the point of view of current theories of emotional appraisal, two points are particularly salient in the present study: firstly, the cognitive meaning of an event is affected by an individual's psychological state (e.g., anxiety, depression, happiness); secondly, how individuals react to a given event, in terms of decision making, social interaction, and emotions experienced, mainly depends on the meaning they attribute to the occurrence [1, 29 - 31]. 


\subsection{Teachers' Negative Emotions: Burnout Syndrome}

Burnout is a prolonged response to chronic emotional and interpersonal stressors encountered in the course of one's work. It has been defined as comprising emotional exhaustion, cynicism, and a decrease in professional accomplishment [32 - 35]. The first of these dimensions, emotional exhaustion, characterized by the inability to accept and manage new emotional situations, is also related to feelings of strain, particularly chronic fatigue resulting from overtaxing work, loss of energy, debilitation, and fatigue [36]. The second dimension, known as cynicism or depersonalization, involves distancing oneself from others, and it has been described as a strategy for coping with stressful events; it has also been characterized in terms of negative or inappropriate attitudes towards clients, irritability, loss of idealism, and withdrawal. Finally, the third dimensions of burnout syndrome is lack of professional fulfillment, leading to feelings of uselessness in relation to one's work and a general lack of confidence in one's own abilities [37].

Given that burnout is a prolonged behavioral, emotional and cognitive response to job stressors, it is usually measured as a continuous variable: this methodological approach has allowed researchers to identify a series of antecedents and consequences of the syndrome [38, 39]. On one hand, major antecedents of burnout have been found to include both professional and personal characteristics. Professional factors comprehend work overload (for example, the perception of having too much work with respect to the available time), role conflict, role ambiguity and the absence or scarcity of job resources; personal factors include low levels of hardiness, external locus of control, low self-esteem, and avoidant coping styles [39]. On the other hand, key job-related outcomes of burnout include: the intention to leave an organization, reduced productivity or capability, low morale, inability to cope, as well as job dissatisfaction, low commitment to the organization, absenteeism, and high turnover [39]. In addition, according to Maslach and Leiter [37], the health outcomes of burnout involve mainly mental and behavioral symptoms rather than physical ones, generally occurring in persons without a history of mental illness.

With specific regard to teachers' risk of developing burnout, research has shown that multiple variables can account for this syndrome in teaching professionals: demographic and job-related personal variables, relations with students, families, colleagues and school principals, social recognition, organizational issues in schools and the broader education system. Concerning demographic and personal job variables, it has been found that age, gender, teaching experience and the level of schooling at which the teacher is operating may each play a role in the development of burnout. More specifically, age and experience are stably associated with the risk of burnout, although it is not yet clear whether being younger and less experienced [40] or older and more experienced [41] leads to greater risk of burnout. Gender and level of school are not consistently related to burnout: while some studies report that male [40, 41] or female [42] (with regard to emotional exhaustion) teachers are more vulnerable to burnout, others show no association between gender and burnout risk [41,35]; similarly, some studies have found that the higher the level of the school in which the teacher works, the higher the risk [41, 43], while other studies report no association between these variables [44]. Concerning relationships, most studies have identified poor relationships with students and colleagues as one of the most accurate predictors of burnout syndrome in teachers, particularly in relation to student misbehavior [45 - 47] and colleagues' lack of collaboration and support [48 - 50]. In the next section, we examine in more detail the contribution of the studentteacher relationship to increased risk of burnout. With regard to social recognition, a number of studies have examined the role of society and teachers' perceived social acknowledgment of their professional role [51, 52]. Concerning organizational issues at the school level and within the education system generally, other studies have explored the role of school reform as a further job stressor for teachers, reporting that the greater teachers' perception of not having enough resources to manage new institutional demands, the greater their risk of developing burnout [53, 54].

\subsection{Teachers' Appraisals of Relational Events and Burnout Risk}

Nowadays, teaching is viewed as a helping profession given that caring for others is a key component of teachers' professional role and practices: this brings to light the crucial role of relationships in teachers' development of burnout $[55,56]$.

The most stressful events for teachers are student misbehavior and failures in the teaching and learning process [33, $48,57,58]$. These job demands can lead teachers to develop burnout, which in turn can seriously compromise their ability to manage student-teacher relationships in terms of treating students in a way that is appropriate and that safeguards the educational relationship [45, 59 - 61]. At the same time, according to appraisal theories, all teachers are not equally influenced by the need to deal with their students' disruptive behavior. The need to manage students' misbehavior may elicit negative emotions or not, depending on teachers' perceptions, appraisals and feelings about the events in question [45]. Recently, Chang [46] found that the higher the intensity of negative emotions perceived in 
response to disruptive behavior on the part of students, the higher the levels of teacher-reported burnout. Specifically, burned-out teachers reported experiencing more negative feelings about students and colleagues and a poorer quality of work-related relationships. Curchod-Ruedi et al. [62] and Authors [57] in two different cultural contexts have found a significant relationship between teachers' expression of disgust towards aggressive pupils and high levels of emotional exhaustion and cynicism. In other words, the more teachers experience burnout syndrome, the more they have difficulty in moderating their displays of negative emotion in the presence of their disruptive students. On the contrary, teachers with low levels of burnout seem better able to regulate their emotion expression. Authors [41] found that job demands placed on teachers, such as managing students' misbehavior was associated with poor mental health, in terms of anxiety and depression symptoms, in a sample of 113 Italian school teachers. Similarly, in a study with 100 UK primary and secondary school teachers, Hastings and Bham [63] reported that teachers' emotional exhaustion was closely related to disrespectful behavior on the part of students. Likewise, Otero Lòpez and colleagues [64] showed that emotional exhaustion, depersonalization and lack of personal accomplishment in a sample of 1386 Spanish teachers were associated with disruptive behavior in students.

In sum, the existing research on burnout in teachers suggests that there is a strong relationship between the burnout phenomenon and teachers' propensity to experience unpleasant emotions (e.g. unhappiness, anger, and frustration) during school-life events. In other words, burnout symptoms may significantly affect teachers' ability to recognize their own emotions and hence to appropriately appraise stressful emotional events [3].

\subsection{The Current Study}

Previous studies lead us to assume that teachers' burnout levels may affect their appraisal of students' emotions and therefore the intensity of their own negative emotions. Thus, the main aim of the present paper was to examine, in a sample of in-service Italian teachers, the associations among their burnout levels, and their emotional appraisal of both their students' emotions and the intensity of their own negative emotions in relation to hypothetical stressful events. Although these key dimensions of professional teaching practice are reported to be correlated with each other in the literature [3, 46, $65-68]$, the relative strength of the direct and indirect relations among them remains to be tested in a full model. We expected that teachers' burnout, evaluated in terms of emotional exhaustion, cynicism and sense of ineffectiveness, would be significantly associated with teachers' emotional appraisal of both students' and their own negative emotions. As a consequence, we set out to evaluate, within a single structural model, the pattern of relationships among all the variables under study, including both direct and indirect predictive effects. We hypothesized that teachers experiencing higher levels of burnout would attribute more intense emotions to their students in the context of stressful events, and that this in turn would intensify their own emotional responses. The ecological validity of the study is twofold. First, it theoretically contributes to shedding new light on the relationship between teachers' negative emotional states and their appraisal of stressful events. Second, the results can help practitioners and researchers to pay due attention to the role of burnout in teachers' perceptions of students' behavior and emotions.

\section{METHOD}

\subsection{Participants}

In-service primary teachers from five Italian schools $(\mathrm{N}=316)$ composed the sample. Mostly female $(92 \%)$ aged from 20 to $60(\mathrm{M}=45.5$; $\mathrm{SD}=12.4)$ with a large experience of teaching ( $82 \%$ over 10 years of teaching). Full-time teachers accounted for $93 \%$ of the sample, and all the participants taught at schools with traditional class sizes of an average of 26 students $(\mathrm{SD}=0.78)$. The teachers were recruited at five different schools located in homogenous socialeconomic and cultural background whose head teachers had authorized the researchers to collect data on-site and during working hours.

\subsection{Instruments and Procedures}

The data were collected via the administration of a protocol with several sections. The first page of the protocol contained a description of the research aims and instructions for completion; participants were also asked to provide some personal demographic information and basic data regarding their teaching careers. The following pages contained the self-report scales measuring teachers' emotional appraisal, by means of the Emotional Competence Questionnaire (ECQ) [64], and their burnout symptoms, via the Maslach Burnout Inventory-Educators Survey (MBI-ES) [69]. 
The ECQ (Italian version) is composed by a simulated scenario aimed to evaluate teachers' appraisal of students' negative emotions as well as their own referred an emotion-eliciting event. The negative emotions evaluated were: disgust, anger, shame, fear, guilt, and sadness. Teachers were asked to imagine a hypothetical situation in which one of their students attacked them verbally, receiving the following description as input: "During break-time you are supervising a large group of students in the corridor. Your attention is attracted by a pupil of your class who is violently pushing another pupil to the ground while speaking offensively to him/her. You go up to them and ask Roberto what is going on. Roberto glares at you and insolently retorts that you should learn to mind your own business". There were two versions of the scenario, one with a male protagonist (Roberto) and one with a female protagonist (Roberta): equal numbers of the two versions were randomly distributed to the sample. Teachers' appraisal process of negative emotions' intensity were measured by two questions: 1) In this situation and after being provoked, which of the following emotions would you attribute to your student and with what degree of intensity? 2) In this situation and after being provoked, which of the following emotions would you feel and with what degree of intensity? The first question is aimed at evaluating teachers' appraisal of emotions' intensity referred to his/her student (SAE, $\alpha=.87$, in the current study). The second question evaluated self-appraisal of emotion referred to themselves (TAE, $\alpha=.81$, in the current study). Responses were given on a 4-point scale from "none" (0) to "very strong" (4). Teachers' answers are given for all the six negative emotions evaluated by the questionnaire. Scores were calculated by summing teachers' appraisal intensity of each of the emotions in both questions. The MBI-ES (Italian version, 69) was adopted to assess the participating teachers' levels of professional burnout. It comprises 22 items covering three different dimensions of professional burnout: emotional exhaustion (EE, 9 items, $\alpha=0.81$, in the current study), cynicism (CY, 5 items, $\alpha=0.71$, in the current study) and sense of ineffectiveness (IN, 8 items, $\alpha=0.76$, in the current study). Responses are given on a 7 -point scale ranging from 0 (never) to 6 (every day).

Two researchers personally distributed the questionnaires to the locations on an individual basis, specifying that they were to be completed independently and agreeing the date by which the completed questionnaires were to be returned. The research was conducted following APA [70] ethical guidelines and code of conduct. Teachers' response rate was $85 \%$.

\subsection{Analytic Strategy}

Preliminary analyses were conducted by a bi-variate analysis to identify potentially confounding inter-relationships among participants' demographic characteristics such as age and gender and the measures under study. Secondly, the univariate distribution of the data was explored for each of the measures. None of the kurtosis and skewness values were in excess of the recommended cut offs $[-1,+1]$. Mahalanobis' distance $(p<.001)$ was calculated for all scores in order to identify and skip any multivariate outliers. As a result, six extreme multivariate cases were omitted from the analysis. Successively, the cumulative network of relationships among the variables of interest was analyzed via structural equation modeling (SEM), implemented by AMOS software [71], version 21.0. This analytical strategy involves statistically testing a hypothesized set of direct and indirect paths among variables to evaluate the extent to which the model fits the empirical data, yielding a measure known as goodness of fit. In the current study, we followed standard recommendations for the evaluation of a given SEM model [72, 73] by adopting two different types of fitindex: absolute and relative. The absolute indexes selected were $\chi^{2}$ and normed $-\chi^{2}(\mathrm{NC})$, a non statistically significant $\chi^{2}$ value, NC values of under 2.0 indicate good fit, the root mean square error of approximation (RMSEA) and the standardized root mean square residual (SRMR). The relative indexes adopted were normed fit index (NFI), nonnormed fit index (NNFI), comparative fit index (CFI) and standardized root mean square residual (SRMR). In this case, the thresholds set for good model fit were: RMSEA $<0.07$ [74], NFI $>0.95$, NNFI $>0.95$ [75], CFI $>0.95$ [73]. The model was specified using participants' scores on the multi-item scales as the observed variables for the latent constructs of burnout (emotional exhaustion, cynicism and sense of ineffectiveness). The target variables were appraisal of both SAE and TAE as measured by mean of ECQ scores.

\section{RESULTS}

The results of the study are presented in two parts: first descriptive statistics and zero-order correlations are reported, then the outcomes of the structural equation model are discussed. All analysis were based on the full sample composed of in-service teachers $(n=310)$. The Bonferroni correction [76] was applied to correct the p-value for this study; the corresponding threshold for statistical significance is set to 0.025 for all analysis. 


\subsection{Descriptive Analysis and Zero-order Correlations among Study Variables}

Table 1 shows zero-order correlations among the scores to Maslach Burnout Inventory (MBI), Emotional Competence Questionnaire (ECQ) and potentially confounding demographic variables (age and gender of participants).

Table 1. Zero-order correlation of the variables included in the study.

\begin{tabular}{|c|c|c|c|c|c|c|c|}
\hline & 1 & 2 & 3 & 4 & 5 & 6 & 7 \\
\hline Emotional Exhaustion (1) & - & & & & & & \\
\hline Cynism (2) & $.270 * *$ & - & & & & & \\
\hline Sense of ineffectiveness (3) & $-.312 * *$ & $-.549 * *$ & - & & & & \\
\hline SAE (4) & $.203 * *$ & $.114^{*}$ & -.033 & - & & & \\
\hline TAE (5) & $.222 * *$ & $.177 * *$ & -.071 & $.465 * *$ & - & & \\
\hline Age (6) & -.095 & $.265 * *$ & -.108 & -.051 & -.012 & - & \\
\hline Gender (7) & -.024 & $-.228 * *$ & .047 & .010 & .004 & -.107 & - \\
\hline
\end{tabular}

Note: $* p<0.025, * * p<0.01$, in bold are reported not statistically significant correlations.

Zero-order correlations analysis revealed that, in general, the relations between two MBI scores and two sub-scales of the ECQ were statistically significant. In particular, emotional exhaustion was positively correlated $(\mathrm{r}=0.203$, $\mathrm{p}<0.01)$ with appraisal of students emotions' intensity (SAE) and their own emotions' intensity (TAE) $(r=0.114, p<0.01)$. In a similar fashion, also the measure of cynicism is positively correlated to both dimensions $(r=0.222, \mathrm{p}<0.01$ for $\mathrm{SAE}$, and $\mathrm{r}=0.177, \mathrm{p}<0.01$ for TAE). In addition, a high positive and statistically significant correlations between SAE and TAE $(\mathrm{r}=0.465, \mathrm{p}<0.01$ ) was found. With regards to potentially confounding variables their role seemed to be trivial (with the exception of small correlations between cynicism, age and gender) and there were consequently skipped from the structural model (this decision involves also the need for parsimony in statistical modeling).

\subsection{Direct and Indirect Effect of MBI on ECQ}

The results of the structural equation model are reported in Fig. (1). The model proposed reported a good fit to the empirical observations.

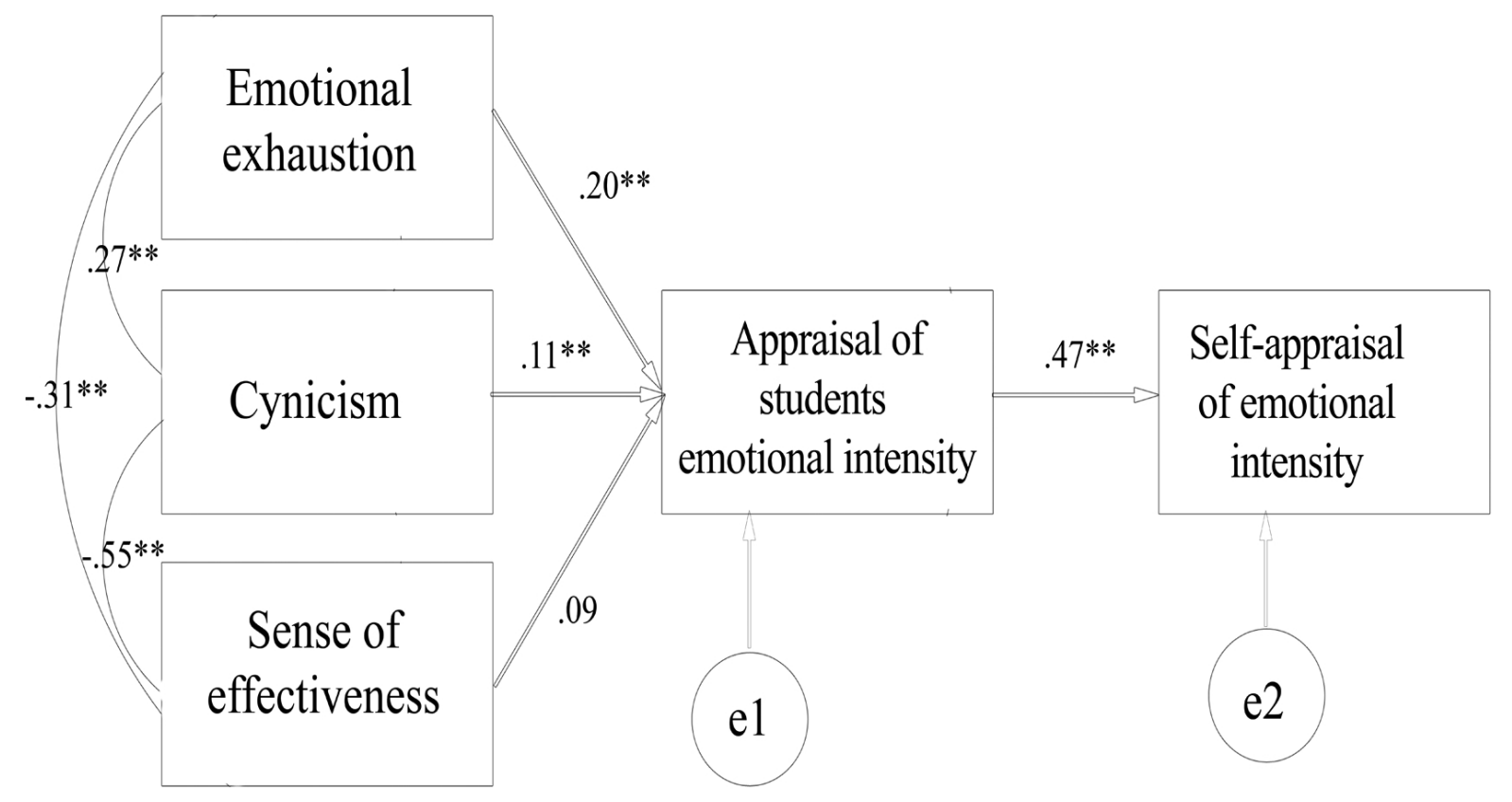

Fig. (1). Final model of burnout sub-scales direct and indirect effect on teachers' appraisal process.

Absolute fit indexes $\left(X^{2}=11.2, \mathrm{p}<.05, \mathrm{NC}=2.24, \mathrm{RMSEA}=0.076, \mathrm{SRMR}=0.048\right)$ are below the recommended values and supported the statistical significance of the model. Similarly, also relative fit index $(\mathrm{NFI}=0.956, \mathrm{NNFI}=0.967$, $\mathrm{CFI}=0.966$ ) supported the practical significance. The analysis of direct effects revealed a moderate positive direct effect of emotional exhaustion $(\beta=0.20, p<0.001)$ and a small direct effect of cynicism $(\beta=0.11, p<0.01)$ on teachers appraisal of student' emotional intensity (SAE). On the contrary the relationship between the sense of ineffectiveness and SAE is 
not statistically significant. With regards to teachers negative emotions' intensity, the model indicated a total (direct + indirect) and positive effect of both emotional exhaustion $(\beta=0.29, \mathrm{p}<0.001)$ and cynicism $(\beta=0.18, \mathrm{p}<0.001)$. Finally a robust direct effect $(\beta=0.49, \mathrm{p}<0.001)$ of SAE on TAE was found. All in all the model suggests two main results. Firstly, only two of three dimensions of burnout (emotional exhaustion and cynicism) contributed to explain teachers' appraisal of students' negative emotions as well as teachers' negative emotions' intensity. Secondly and consequently, teachers' appraisal of students' emotions intensity contributed to explain teachers' appraisal of their own negative emotions' intensity.

\section{DISCUSSION AND CONCLUSION}

The aim of the current study was to analyze the relationships among teacher's levels of burnout - evaluated by means of the three classic burnout sub-scales, labeled emotion exhaustion, cynicism and ineffectiveness - and their appraisal of intense negative emotions in the context of hypothetical conflicts with their students. Although we did not focus on socio-demographic dimensions, we controlled for their potential effect on the variables under study, finding no significant relationship between two dimensions of burnout (i.e. emotional exhaustion and ineffectiveness) and teachers' age and gender. On the other hand, a significant correlation was found with cynicism. Furthermore, teachers' gender and age were not associated with their scores on either of the two measures of their emotional appraisal. Previous research has yielded conflicting results with respect to the associations between burnout and socio-demographic variables, suggesting that further latent variables may be at play in these relationships $[77,78]$. With regard to teachers' sense of ineffectiveness, while it was significantly associated with the other dimensions of burnout as expected, it was found to play a different role to exhaustion and cynicism in relation to emotional appraisal [33]. Specifically, in this study the burnout scale labeled "sense of ineffectiveness or accomplishment" did not affect teachers's appraisal of elicitingemotion event. These results are in line with the analysis of Maslach and Leiter [37], who proposed that of the three MBI dimensions, exhaustion and cynicism are the two primary measures of burnout. More specifically, it seems that exhaustion and cynicism constitute the essence or core of burnout syndrome [68, 79, 80].

Our key aim was to simultaneously investigate the direct and indirect influences of each of the dimensions of burnout on teachers' emotional appraisal processes. Following appraisal theory [2] and in light of recent findings showing that both positive and negative emotional states affect people's appraisal of events [1, 18, 23, 81], we expected that our main hypothesis would be confirmed. Overall, the findings provided support for our assumptions in the present study, showing that burned-out teachers are more like to report intense negative emotions during a verbal conflict with a misbehaving student. Furthermore, the full tested model showed that teachers' emotional exhaustion and cynicism had a direct effect on their appraisal of their students' emotions, and an indirect effect on their appraisal of their own emotions. In the next section, we discuss how our main findings may be interpreted and explore their implications for educational settings. However, it should be taken into consideration that our results might be explained by the personal characteristics of the participating teachers: for example, it is possible that more sensitive teachers may be, at the same time, more vulnerable to burnout and more prone to perceiving more intense emotions than less emotionally-sensitive colleagues. Another key influence may be the school environment and perceived practical and social support: when teachers perceive that their school is well-equipped to overcome difficulties and manage misbehavior, they report enhanced wellbeing [82 - 84].

\subsection{Why High Perceived Negative Emotion Intensity is associated with Burnout in Teachers}

Accordingly to previous studies, teachers' emotional exhaustion and cynicism are both positively related with high levels of negative emotions [45, 66]. Among the three sub-scales of burnout, emotional exhaustion displays the strongest association with negative emotion intensity, when compared with cynicism and ineffectiveness. Indeed, numerous studies have borne out the strong relationship between emotional exhaustion in teachers and a range of unpleasant emotions, including anxiety, anger and frustration, guilt and shame, and sadness [85]. There appears to be a key link between how teachers feel about their daily work and the intensity of their own negative emotions. Specifically, teachers' perceptions of student discipline can be related to their levels of emotional exhaustion and overall burnout $[3,8,59,86,87]$. In a study with 1,939 German teachers, Klusmann and colleagues [88] found that student discipline, as perceived by both teachers and principals, was inversely related to teachers' emotional exhaustion. Analogously, Wang, Hall and Rahimi [89] showed, in a study on 523 teachers, that emotional exhaustion was negatively related to teachers' appraisal of students' engagement in classroom activities and learning processes. Our study showed that teachers' appraisal of their own emotions was associated with their appraisal their students' behavior and emotions. The strong association between their evaluations of their student's emotion intensity (SAE) and their self- 
appraisal of their own emotions (TAE) suggest that when teachers experience events characterized by high levels of emotional intensity (such as children that display aggressive behaviors or a "difficult" classroom) their own emotional intensity is affected too. As reported by Tsouloupas and colleagues [47], teachers' emotional exhaustion is closely related to the intensity of the negative emotions experienced by both teachers and students during their interactions.

A key finding of the current study was the fact that only the emotional exhaustion sub-scale was correlated with negative emotion intensity. This is consistent with studies that have reported emotional exhaustion as the MBI scale with the greatest power to describe the construct [57, 90,91]. As other studies [48] suggest, emotional exhaustion is the most explicative scale, when it comes to defining burnout and identifying its associations with other variables. Many authors, indeed, consider burnout to mainly consist of a worker's perceived exhaustion, from a physical, mental, and emotional point of view [91].

\subsection{Why Burned-out Teachers are at Risk of Failure in Their Emotional Appraisal Process}

Emotional malaise modifies the way people perceive and appraise reality [92]. When in a state of burnout, workers express their emotional fatigue and withdrawal in terms of emotional exhaustion and cynicism. These experiences bear a wide range of consequences in workers' lives, such as dis-improved performance, reduced care with their duties [93], negative attitudes towards students [94, 95], intention to leave their current post [56]. Most of these effects are underpinned by a shift in how workers perceive their workplace and professional role: for example, anger and fear (addressed in the current study) are usually related to a perception of threat [1]. The direct and indirect effects identified in the current model suggest two main implications of burnout. The direct effect of teachers' levels of burnout on their appraisal of students' emotions indicates that teachers, when emotionally fatigued, tend to appraise their working conditions more negatively, therefore perceiving their students' negative emotions as particularly intense. A possible explanation is that burned-out teachers perceive the school or classroom context as more threatening than before they developed such negative reactions: as a consequence, detachment and cynicism may act as coping strategies, given that they allow teachers to protect themselves from the "emotional threats" they perceive [57, 82, 90]. At the same time, the indirect effect means that, because of the intense negativity perceived at school, their emotional experience is further compromised, therefore generating a recursive impact on their burnout condition. This process may have major consequences, in terms of reducing teachers' wellbeing and worsening the quality of teacher-student relationships [94]. In this regard, Jennings and Greenberg [95] have coined the term "burnout cascade" to describe the potentially devastating effects on relationships with students and classroom management that may be incurred by burned-out teachers who have lost the energy to invest in the emotional dimension of their work.

\subsection{Limitations and Future Research Directions}

Some limitations of present study should be discussed. Firstly, the findings mainly concern teachers' appraisal of students' and their own emotion intensity. A multi-method approach to data collection would provide more reliable results and reduce the risks associated with evaluating complex processes via a single indicator such as the emotional intensity elicited by stressful events. Furthermore, it should be noted that appraisal theory is challenged in part by findings from neurophysiological research on emotion processing that point up the key role of the subconscious in shaping people's emotional responses to adverse stimuli [96]. Hence, analysis of people's appraisal of emotion events ideally requires a mixed-method research design that includes both cognitive awareness and unconscious factors.

We also plan to collect new longitudinal data, adopting the continuous time mediation approach recommended by Deboeck and Preacher [97] to minimize the issues associated with time-lag analysis. More specifically, longitudinal studies will offer a key opportunity to test sequential hypotheses concerning both the direct and indirect effects of teachers' burnout on their emotional and cognitive wellbeing.

Furthermore, our model did not include demographic variables such as marital status and social background, given the unclear findings about the effects of these factors reported in the existing literature [39]: nonetheless, future research may shed new light on the role of demographics as well as psychological characteristics which affect how teachers experience burnout. In addition, in light of the fact that teachers' job-related stress may intensify in the course of the academic year, future research should measure teachers' emotion intensity at different times during the school year.

Finally, our results prompt us to further analyze whether burned-out teachers overestimate their students' negative emotions in real life also. According to Sutton and Wheatley [3], teachers' emotional processes during their interaction with others need to be observed to advance our understanding of the workings of emotion comprehension and regulation during social interactions. Likewise, self-report measures and the social desirability effect may lead teachers 
to self-evaluate a lower level of negative emotion intensity towards their students. Finally, as suggested by Sutton and Wheatley [3], it may be of interest to study whether emotional appraisal differs between more experienced and novice teachers, or whether teachers working at different levels of schooling may appraise differently.

\section{ETHICS APPROVAL AND CONSENT TO PARTICIPATE}

Not applicable.

\section{HUMAN AND ANIMAL RIGHTS}

No animals/humans were used for studies that are base of this research.

\section{CONSENT FOR PUBLICATION}

Not applicable.

\section{CONFLICT OF INTEREST}

The authors declare no conflict of interest, financial or otherwise.

\section{ACKNOWLEDGEMENTS}

Declared none.

\section{REFRENCES}

[1] Gross JJ. Emotion regulation: Affective, cognitive, and social consequences. Psychophysiology 2002; 39(3): 281-91 [http://dx.doi.org/10.1017/S0048577201393198] [PMID: 12212647]

[2] Fiorilli C, De Stasio S, Chiacchio C, Chan SM. Emotion socialization practices in Italian and Hong Kong-Chinese mothers. SpringerPlus 2015; 4(1): 758

[3] Sutton RE, Wheatley KF. Teachers' emotions and teaching: A review of the literature and directions for future research. Educ Psychol Rev 2003; 15(4): 327-58. [http://dx.doi.org/10.1023/A:1026131715856]

[4] Sutton RE, Mudrey-Camino R, Knight CC. Teachers' emotion regulation and classroom management. Theory Pract 2009; $48(2)$ : 130-7. [http://dx.doi.org/10.1080/00405840902776418]

[5] Roseman IJ, Smith CA. Appraisal theory: Overview, assumptions, varieties, controversies. In: Appraisal processes in emotion: Theory, methods, research. New York, NY, US: Oxford University Press 2011; pp. 3-19.

[6] López J, Gil R, García R, Cearreta I, Garay N. Towards an ontology for describing emotions. Emerging Technol Inf Syst Knowl Soc 2008; 5: 96-104.

[http://dx.doi.org/10.1007/978-3-540-87781-3_11]

[7] De Stasio S, Fiorilli C, Di Chiacchio C. Effects of verbal ability and fluid intelligence on children's emotion understanding. Int J Psychol 2014; 49(5): 409-14.

[8] Becker ES, Keller MM, Goetz T, Frenzel AC, Taxer JL. Antecedents of teachers' emotions in the classroom: An intraindividual approach. Front Psychol 2015; 6: 635.

[http://dx.doi.org/10.3389/fpsyg.2015.00635] [PMID: 26042067]

[9] Brans K, Verduyn P. Intensity and duration of negative emotions: Comparing the role of appraisals and regulation strategies. PLoS One 2014; 9(3): e92410.

[http://dx.doi.org/10.1371/journal.pone.0092410] [PMID: 24670979]

[10] Sonnemans J, Frijda N. The determinants of subjective emotional intensity. Cogn Emotion 1995; 9: $483-506$. [http://dx.doi.org/10.1080/02699939508408977]

[11] Fiorilli C, Gabola P, Pepe A, et al. The effect of teachers' emotional intensity and social support on burnout syndrome. A comparison between Italy and Switzerland. Revue Européenne de Psychologie Appliquée/European. Review of Applied Psychology 2015; 65(6): 275-83.

[12] Lemerise EA, Arsenio WF. An integrated model of emotion processes and cognition in social information processing. Child Dev 2000; 71(1): 107-18. [http://dx.doi.org/10.1111/1467-8624.00124] [PMID: 10836564]

[13] Magai C, McFadden SH. The role of emotions in social and personality development. New York: Plenum Press 1995.

[14] Saarni C. The development of emotional competence. New York: Guilford Press 1999.

[15] Lazarus RS. Emotions and interpersonal relationships: Toward a person-centered conceptualization of emotions and coping. J Pers 2006; 74(1): 9-46

[http://dx.doi.org/10.1111/j.1467-6494.2005.00368.x] [PMID: 16451225] 
[16] Artuso C, Palladino P, Ricciardelli P. Social updating: the role of gaze direction in updating and memorizing emotional faces. Soc Cogn 2015; 33(6): 543-61. [http://dx.doi.org/10.1521/soco.2015.33.6.543]

[17] Mumenthaler C, Sander D. Social appraisal influences recognition of emotions. J Pers Soc Psychol 2012; $102(6)$ : $1118-35$. [http://dx.doi.org/10.1037/a0026885] [PMID: 22288528]

[18] Goldin PR, McRae K, Ramel W, Gross JJ. The neural bases of emotion regulation: Reappraisal and suppression of negative emotion. Biol Psychiatry 2008; 63(6): 577-86. [http://dx.doi.org/10.1016/j.biopsych.2007.05.031] [PMID: 17888411]

[19] Surguladze SA, Young AW, Senior C, Brébion G, Travis MJ, Phillips ML. Recognition accuracy and response bias to happy and sad facial expressions in patients with major depression. Neuropsychology 2004; 18(2): 212-8. [http://dx.doi.org/10.1037/0894-4105.18.2.212] [PMID: 15099143]

[20] Ochsner KN, Phelps E. Emerging perspectives on emotion-cognition interactions. Trends Cogn Sci (Regul Ed) 2007; 11(8): 317-8. [http://dx.doi.org/10.1016/j.tics.2007.06.008] [PMID: 17631410]

[21] Lerner JS, Li Y, Valdesolo P, Kassam KS. Emotion and decision making. Annu Rev Psychol 2015; 66: 799-823. [http://dx.doi.org/10.1146/annurev-psych-010213-115043] [PMID: 25251484]

[22] Phelps EA, Lempert KM, Sokol-Hessner P. Emotion and decision making: multiple modulatory neural circuits. Annu Rev Neurosci 2014; 37: 263-87.

[http://dx.doi.org/10.1146/annurev-neuro-071013-014119] [PMID: 24905597]

[23] Angie AD, Connelly S, Waples EP, Kligyte V. The influence of discrete emotions on judgement and decision-making: A meta-analytic review. Cogn Emotion 2011; 25(8): 1393-422 [http://dx.doi.org/10.1080/02699931.2010.550751] [PMID: 21500048]

[24] Coupland NJ, Sustrik RA, Ting P, et al. Positive and negative affect differentially influence identification of facial emotions. Depress Anxiety 2004; 19(1): 31-4 [http://dx.doi.org/10.1002/da.10136] [PMID: 14978783]

[25] Schmidt PC, Mast MS. Mood effects on emotion recognition. Motiv Emot 2010; 34(3): 288-92. [http://dx.doi.org/10.1007/s11031-010-9170-0]

[26] Lee TM, Ng EH, Tang SW, Chan CC. Effects of sad mood on facial emotion recognition in Chinese people. Psychiatry Res 2008; 159(1-2): 37-43. [http://dx.doi.org/10.1016/j.psychres.2007.04.022] [PMID: 18329723]

[27] Berking M, Whitley B. Emotion regulation: Definition and relevance for mental health. In: Affect Regulation Training. New York: Springer 2014; pp. 5-17.

[http://dx.doi.org/10.1007/978-1-4939-1022-9_2]

[28] Frijda NH. The laws of emotion. Mahwah: Erlbaum 2007.

[29] Campos JJ, Frankel CB, Camras L. On the nature of emotion regulation. Child Dev 2004; 75(2): $377-94$ [http://dx.doi.org/10.1111/j.1467-8624.2004.00681.x] [PMID: 15056194]

[30] Keltner D, Kring AM. Emotion, social function, and psychopathology. Rev Gen Psychol 1998; 2(3): 320. [http://dx.doi.org/10.1037/1089-2680.2.3.320]

[31] Punkanen M, Eerola T, Erkkilä J. Biased emotional recognition in depression: perception of emotions in music by depressed patients. J Affect Disord 2011; 130(1-2): 118-26. [http://dx.doi.org/10.1016/j.jad.2010.10.034] [PMID: 21071094]

[32] Fiorilli C, De Stasio S, Benevene P, Iezzi F, Pepe A, Albanese O. Copenhagen burnout inventory (CBI): A validation study in an Italian teacher group Testing, Psychometrics, Methodology: TPM: Appl Psychol. 2015; 22(4): 537-51.

[33] Hakanen JJ, Bakker AB, Schaufeli WB. Burnout and work engagement among teachers. J Sch Psychol 2006; 43(6): 495-513. [http://dx.doi.org/10.1016/j.jsp.2005.11.001]

[34] Stoeber J, Rennert D. Perfectionism in school teachers: relations with stress appraisals, coping styles, and burnout. Anxiety Stress Coping 2008; 21(1): 37-53 [http://dx.doi.org/10.1080/10615800701742461] [PMID: 18027123]

[35] Williams J, Dikes C. The implications of demographic variables as related to burnout among a sample of special education teachers. Education 2015; 135(3): 337-45.

[36] Maslach C, Leiter MP. Understanding the burnout experience: Recent research and its implications for psychiatry. World Psychiatry 2016; 15(2): 103-11 [http://dx.doi.org/10.1002/wps.20311] [PMID: 27265691]

[37] Maslach C, Leiter MP. Early predictors of job burnout and engagement. J Appl Psychol 2008; 93(3): 498-512 [http://dx.doi.org/10.1037/0021-9010.93.3.498] [PMID: 18457483]

[38] Bakker AB, Costa PL. Chronic job burnout and daily functioning: A theoretical analysis. Burn Res 2014; 1(3): 112-9. [http://dx.doi.org/10.1016/j.burn.2014.04.003] 
[39] Maslach C, Schaufeli WB, Leiter MP. Job burnout. Annu Rev Psychol 2001; 52(1): 397-422. [http://dx.doi.org/10.1146/annurev.psych.52.1.397] [PMID: 11148311]

[40] Lau PY, Yuen MT, Chan RC. Do demographic characteristics make a difference to burnout among hong kong secondary school teachers? Soc Indic Res 2005; 71(1-3): 491-516. [http://dx.doi.org/10.1007/s11205-004-8033-z]

[41] Fiorilli C, Albanese O, Gabola P, Pepe A. Teachers' emotional competence and social support: Assessing the mediating role of teacher burnout. Scand J Edu Res 2017; 61(2): 127-38.

[42] Shaheen F, Mahmood N. Demographic variables as determinants of emotional burnout among public school teachers. J Res Refl Edu 2016; 10(1): $37-50$.

[43] De Stasio S, Fiorilli C, Benevene P, Uusitalo $₫$ Malmivaara L, Di Chiacchio C. Burnout in Special needs teachers at kindergarten and primary school: Investigating the role Of personal resources and work wellbeing. psychology in the schools 2017; 54: $472-86$.

[44] Pas ET, Bradshaw CP, Hershfeldt PA. Teacher- and school-level predictors of teacher efficacy and burnout: identifying potential areas for support. J Sch Psychol 2012; 50(1): 129-45.

[http://dx.doi.org/10.1016/j.jsp.2011.07.003] [PMID: 22386082]

[45] Chang ML. An appraisal perspective of teacher burnout: Examining the emotional work of teachers. Educ Psychol Rev 2009; 21(3): 193-218. [http://dx.doi.org/10.1007/s10648-009-9106-y]

[46] Chang ML. Toward a theoretical model to understand teacher emotions and teacher burnout in the context of student misbehavior: Appraisal, regulation and coping. Motiv Emot 2013; 37(4): 799-817.

[http://dx.doi.org/10.1007/s11031-012-9335-0]

[47] Tsouloupas CN, Carson RL, Matthews R, Grawitch MJ, Barber LK. Exploring the association between teachers' perceived student misbehaviour and emotional exhaustion: The importance of teacher efficacy beliefs and emotion regulation. Educ Psychol 2010; 30(2): $173-89$

[http://dx.doi.org/10.1080/01443410903494460]

[48] Di Chiacchio C, De Stasio S, Fiorilli C. Examining how motivation toward science contributes to omitting behaviours in the Italian PISA 2006 sample. Learning and Individual Differences 2016; 50: 56-63. [http://dx.doi.org/10.1016/j.lindif.2016.06.025]

[49] Kahn JH, Schneider KT, Jenkins-Henkelman TM, Moyle LL. Emotional social support and job burnout among high-school teachers: is it all due to dispositional affectivity? J Organ Behav 2006; 27(6): 793-807. [http://dx.doi.org/10.1002/job.397]

[50] Kinman G, Wray S, Strange C. Emotional labour, burnout and job satisfaction in UK teachers: The role of workplace social support. Educ Psychol 2011; 31(7): 843-56.

[http://dx.doi.org/10.1080/01443410.2011.608650]

[51] Lowenstein LF. Teacher stress leading to burnout: Its prevention and cure. Education Today 1991; 41(2): 12-6.

[52] OECD. TALIS 2013 results: An international perspective on teaching and learning. OECD Publishing 2014

[53] Dworkin A. Perspectives on teacher burnout and school reform. Int Educ J 2001; 2(2): 69-78.

[54] Tsang K, Kwong T. Teachers' emotions in the context of education reform: labor process theory and social constructionism. Br J Sociol Educ 2016; 3: 1-12.

[55] Morse G, Salyers MP, Rollins AL, Monroe-DeVita M, Pfahler C. Burnout in mental health services: a review of the problem and its remediation. Adm Policy Ment Health 2012; 39(5): 341-52. [http://dx.doi.org/10.1007/s10488-011-0352-1] [PMID: 21533847]

[56] Schaufeli WB, Bakker AB. Job demands, job resources, and their relationship with burnout and engagement: A multi sample study. J Organ Behav 2004; 25(3): 293-315. [http://dx.doi.org/10.1002/job.248]

[57] Fiorilli C, De Stasio S, Di Chicchio C, Pepe A, Salmela-Aro K. School burnout, depressive symptoms and engagement: Their combined effect on student achievement. Int J Edu Res 2017; 84(1): 12.

[58] Skaalvik EM, Skaalvik S. Teacher job satisfaction and motivation to leave the teaching profession: Relations with school context, feeling of belonging, and emotional exhaustion. Teach Teach Educ 2011; 27(6): 1029-38. [http://dx.doi.org/10.1016/j.tate.2011.04.001]

[59] Emmer ET, Stough LM. Classroom management: A critical part of educational psychology, with implications for teacher education. Educ Psychol 2001; 36(2): 103-12. [http://dx.doi.org/10.1207/S15326985EP3602_5]

[60] Evers WJ, Tomic W, Brouwers A. Burnout among teachers students' and teachers' perceptions compared. Sch Psychol Int 2004; 25(2): 131-48. [http://dx.doi.org/10.1177/0143034304043670]

[61] Pines AM. Teacher burnout: A psycho-dynamic existential perspective. Teach Teach 2002; 8(2): 121-40. [http://dx.doi.org/10.1080/13540600220127331] 
[62] Curchod-Ruedi D, Doudin PA, Moreau J. La compréhension des émotions à l'école. In: Approches affectives, métacognitives et cognitives de la compréhension. Québec: PUQ 2010; pp. 149-67.

[63] Hastings RP, Bham MS. The relationship between student behaviour patterns and teacher burnout. Sch Psychol Int 2003; 24(1): 115-27. [http://dx.doi.org/10.1177/0143034303024001905]

[64] Otero López JM, Santiago MJ, Godás A, Castro C, Villardefrancos E, Ponte D. An integrative approach to burnout in secondary school teachers: Examining the role of student disruptive behaviour and disciplinary issues. Int J Psychol Psychol Ther $2008 ; 8: 2$.

[65] Doudin PA, Curchod-Ruedi D. La compréhension des émotions et pratiques de réintégration [The understanding of emotions and reintegration practices]. In: Intervenir auprès des élèves ayant besoins particuliers: quelle formation à l'enseignement? [Intervening with pupils having specific needs: what training in teaching?]. Québec: PUQ 2010; pp. 145-63.

[66] Brackett MA, Palomera R, Mojsa $\square$ Kaja J, Reyes MR, Salovey P. Emotion-regulation ability, burnout, and job satisfaction among British secondary-school teachers. Psychol Sch 2010; 47(4): 406-17.

[67] Verhoeven C, Kraaij V, Joekes K, Maes S. Job conditions and wellness/health outcomes in Dutch secondary school teachers. Psychol Health 2003; 18(4): 473-87.

[http://dx.doi.org/10.1080/0887044031000147201]

[68] Maslach C, Jackson SE, Leiter MP. Maslach burnout inventory manual. 3rd ed. Mountain View, California: CPP, Inc 1996.

[69] Sirigatti S, Stefanile C. Aspetti e problemi dell'adattamento italiano del MBI. Boll Psicol Appl 1992; $202: 3-12$.

[70] Publication manual of the American Psychological Association. 6th ed. Washington, DC: Author 2010.

[71] Arbuckle JL. AMOS 70 User guide. Spring House, PA: Amos Development 2006.

[72] Bagozzi RP, Yi Y, Nassen KD. Representation of measurement error in marketing variables: Review of approaches and extension to threefacet designs. J Econom 1998; 89(1): 393-421. [http://dx.doi.org/10.1016/S0304-4076(98)00068-2]

[73] Hu L, Bentler PM. Cutoff criteria for fit indexes in covariance structure analysis: Conventional criteria versus new alternatives. Struct Equ Modeling 1999; 6: 1-55. [http://dx.doi.org/10.1080/10705519909540118]

[74] Schermelleh-Engel K, Moosbrugger H, Müller H. Evaluating the fit of structural equation models: Tests of significance and descriptive goodness-of-fit measures. Methods Psychol Res Online 2003; 8(2): 23-74.

[75] Marsh HW, Hau KT, Wen Z. In search of golden rules: Comment on hypothesis-testing approaches to setting cutoff values for fit indexes and dangers in overgeneralizing findings. Struct Equ Modeling 2001; 11(3): 320-41. [http://dx.doi.org/10.1207/s15328007sem1103_2]

[76] Bland JM, Altman DG. Comparing methods of measurement: Why plotting difference against standard method is misleading. Lancet 1995; 346(8982): 1085-7. [http://dx.doi.org/10.1016/S0140-6736(95)91748-9] [PMID: 7564793]

[77] van Droogenbroeck F, Spruyt B, Vanroelen C. Burnout among senior teachers: Investigating the role of workload and interpersonal relationships at work. Teach Teach Educ 2014; 43: 99-109. [http://dx.doi.org/10.1016/j.tate.2014.07.005]

[78] Zabel RH, Zabel MK. Revisiting burnout among special education teachers: Do age, experience, and preparation still matter? Teach Educ Spec Educ 2001; 24: 128-39. [http://dx.doi.org/10.1177/088840640102400207]

[79] Schaufeli W, Enzmann D. The burnout companion to study and practice: A critical analysis. CRC press $1998 ; 224$.

[80] Schaufeli W, Bunk BP. Burnout. An overview of 25 years of research and theorizing JA: Winnubst and C. 1998 ; 2: pp. 282-424.

[81] Keller MM, Chang ML, Becker ES, Goetz T, Frenzel AC. Teachers' emotional experiences and exhaustion as predictors of emotional labor in the classroom: An experience sampling study. Front Psychol 2014; 5: 1442. [http://dx.doi.org/10.3389/fpsyg.2014.01442] [PMID: 25566124]

[82] Benevene P, Fiorilli C. Burnout syndrome at school: A comparison study with lay and consecrated Italian teachers. Mediterr J Soc Sci 2015; 6(1): 501-6.

[83] Hoy WK, Miskel CG. Theory, Research, and practice. Educational administration, New York: Random House Inc. 2008.

[84] Klassen RM, Chiu MM. Effects on teachers' self-efficacy and job satisfaction: Teacher gender, years of experience, and job stress. J Educ Psychol 2010; 102(3): 741-56. [http://dx.doi.org/10.1037/a0019237]

[85] Bullough RV, Mortensen Bullough DA, Blackwell Mayes P. Getting in touch: Dreaming, the emotions and the work of teaching. Teach Teach 2006; 12(2): 193-208 [http://dx.doi.org/10.1080/13450600500467399]

[86] van Veen K, Sleegers P. How does it feel? Teachers' emotions in a context of change. J Curric Stud 2006; 38(1): 85-111 [http://dx.doi.org/10.1080/00220270500109304] 
[87] Wheatley SL, Brugha TS, Shapiro DA. Exploring and enhancing engagement to the psychosocial intervention 'Preparing for Parenthood'. Arch Women Ment Health 2003; 6(4): 275-85. [http://dx.doi.org/10.1007/s00737-003-0025-5] [PMID: 14628180]

[88] Klusmann U, Kunter M, Trautwein U, Lüdtke O, Baumert J. Teachers' occupational well-being and quality of instruction: The important role of self-regulatory patterns. J Educ Psychol 2008; 100(3): 702. [http://dx.doi.org/10.1037/0022-0663.100.3.702]

[89] Wang H, Hall NC, Rahimi S. Self-efficacy and causal attributions in teachers: Effects on burnout, job satisfaction, illness, and quitting intentions. Teach Teach Educ 2015; 47: 120-30. [http://dx.doi.org/10.1016/j.tate.2014.12.005]

[90] Kristensen TS, Borritz M, Villadsen E, Christensen KB. The copenhagen burnout inventory: A new tool for the assessment of burnout. Work Stress 2005; 19(3): 192-207. [http://dx.doi.org/10.1080/02678370500297720]

[91] Schaufeli WB, Greenglass ER. Introduction to special issue on burnout and health. Psychol Health 2001; 16(5): 501-10. [http://dx.doi.org/10.1080/08870440108405523] [PMID: 22804495]

[92] Scherer KR. On the rationality of emotions: or, When are emotions rational? Soc Sci Inf (Paris) 2011; 50(3-4): 330-50 [http://dx.doi.org/10.1177/0539018411411018]

[93] Fogarty TJ, Singh J, Rhoads GK, Moore RK. Antecedents and consequences of burnout in accounting: Beyond the role stress model. Behav Res Account 2000; 12: 31-67.

[94] Aloe AM, Shisler SM, Norris BD, Nickerson AB, Rinker TW. A multivariate meta-analysis of student misbehavior and teacher burnout. Educ Res Rev 2014; 12: 30-44. [http://dx.doi.org/10.1016/j.edurev.2014.05.003]

[95] Jennings PA, Greenberg MT. The prosocial classroom: Teacher social and emotional competence in relation to student and classroom outcomes. Rev Educ Res 2009; 79(1): 491-525. [http://dx.doi.org/10.3102/0034654308325693]

[96] Phelps EA, LeDoux JE. Contributions of the amygdala to emotion processing: From animal models to human behavior. Neuron 2005; 48(2): 175-87.

[http://dx.doi.org/10.1016/j.neuron.2005.09.025] [PMID: 16242399]

[97] Deboeck PR, Preacher KJ. No need to be discrete: A method for continuous time mediation analysis. Struct Equ Modeling 2016; 23(1): 61-75. [http://dx.doi.org/10.1080/10705511.2014.973960]

\section{(C) 2017 Fiorilli et al.}

This is an open access article distributed under the terms of the Creative Commons Attribution 4.0 International Public License (CC-BY 4.0), a copy of which is available at: (https:/creativecommons.org/licenses/by/4.0/legalcode). This license permits unrestricted use, distribution, and reproduction in any medium, provided the original author and source are credited. 